\title{
Continuous Venovenous Hemofiltration is Associated with Improved Survival in Burn Patients with Shock: A Subset Analysis of a Multicenter Observational Study
}

\author{
David M. Hill ${ }^{a}$ Julie A. Rizzo ${ }^{\text {b, c }}$ James K. Aden ${ }^{d}$ William L. Hickerson ${ }^{a}$ \\ Kevin K. Chung ${ }^{c}$ RESCUE Investigators

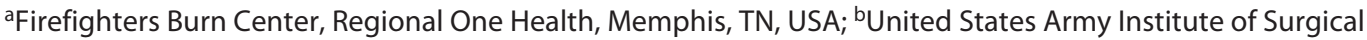 \\ Research, Fort Sam Houston, TX, USA; 'Department of Medicine, Uniformed Services University of the Health \\ Sciences, Bethesda, MD, USA; ${ }^{\mathrm{d} B r o o k e}$ Army Medical Center, Fort Sam Houston, TX, USA
}

\section{Keywords}

Burns · Acute kidney injury · Renal replacement therapy ·

Hemofiltration · Multicenter

\begin{abstract}
Introduction: Acute kidney injury (AKI) is associated with high mortality in burn patients. Previously, we reported that timely initiation of renal replacement therapy (RRT) with an individualized preference toward continuous modes at relatively higher than recommended doses has become standard practice in critically ill burn patients with AKI and is associated with a historically low mortality. The purpose of this cohort analysis was to determine if modality choice impacted survival in burn patients. Methods: After Institutional Review Board approval, a subset analysis was performed on deidentified data collected during a multicenter, observational study. All patients ( $n=170$ ) were 18 years or older, admitted with severe burn injuries and started on RRT. Comparisons were made utilizing $X^{2}$ or Fisher's exact test. Kaplan-Meier plots were utilized to assess survival. Sample size determinations to aid future research were calculated utilizing $X^{2}$ test with a Yates Correction Factor. Results: Demographics and revised Baux were similar between groups. When continu-
\end{abstract}

karger@karger.com www.karger.com/bpu

Karger ${ }^{\prime \prime} \div$

BOPEN ACCESS
(C) 2020 The Author(s)

Published by S. Karger AG, Basel

This article is licensed under the Creative Commons AttributionNonCommercial-NoDerivatives 4.0 International License (CC BY NC-ND) (http://www.karger.com/Services/OpenAccessLicense) Usage and distribution for commercial purposes as well as any distribution of modified material requires written permission. ous venovenous hemofiltration (CVVH) was compared to all other modalities, there was no statistically significant difference in survival ( 56 vs. $43 \%, p=0.124$ ). However, survival was significantly improved (54 vs. $37 \%, p=0.032$ ) in the subset of patients requiring vasopressors $(n=77)$. There was no statistically significant survival difference in patients with inhalation injury (38vs. $29 \%, p=0.638$ ) or acute lung injury/acute respiratory distress syndrome (51 vs. $33 \%, p=0.11$ ). Discussion/Conclusion: Survival may be improved if CVVH is chosen as the preferred modality in burn patients with shock and requiring RRT. Differences in other subsets were promising, but analysis was underpowered. Further research should determine if modality choice provides survival benefit in any other subset of burn injury.

(c) 2020 The Author(s)

Published by S. Karger AG, Basel

\section{Background}

Acute kidney injury (AKI) significantly complicates the hospital course of critically ill patients. Increased utilization of renal replacement therapies (RRTs) and advancements in the technology has reduced mortality [1, 2]. Despite improved outcomes, there is a lack of consen- 
sus regarding many aspects of RRT to include modality, timing of initiation, and dose [3-9]. Varying trial designs and target populations make direct comparison of studies difficult $[10,11]$. Ultimately, the choice of modality often comes down to prescriber preference and availability.

In patients with severe burn injuries, development of AKI is associated with longer length of stay and higher mortality [12-14]. Early choice of continuous venovenous hemofiltration $(\mathrm{CVVH})$ over traditional dialysis was identified to improve survival and reduce vasopressor requirements in severe burn patients with AKI [2]. During the RESCUE trial, use of high-volume hemofiltration (HVHF), $70 \mathrm{~mL} / \mathrm{kg} / \mathrm{h}$, in burn patients with shock reduced 48-h vasopressor requirements and 14-day Multiple Organ Dysfunction Score, as compared to standard doses $(20-35 \mathrm{~mL} / \mathrm{kg} / \mathrm{h})$ [5]. Concurrently, a multicenter observational study was performed to evaluate RRT practices and outcomes among severely injured burn patients [3]. We found centers initiated therapy early, preferred $\mathrm{CVVH}$, and demonstrated reduced mortality and similarly better full renal recovery rates, as compared to other studies [15-21]. The purpose of this subset analysis of the study cohort was to determine if modality characteristics of RRT impacted survival.

\section{Methods}

Multilevel, Institutional Review Board approval was obtained to conduct this multicenter, observational study. Ten burn centers participated from February 2012 to February 2016. All patients or their legal authorized representative gave consent prior to enrolling in the study.

\section{Patients}

The observational study enrolled patients placed on RRT for any indication, but not enrolled in the concurrent RESCUE trial (NCT01213914). All adult patients 18 years or older, admitted with severe burns, and placed on continuous RRT for acute indications were included. Patients were excluded if they were on dialysis for ESRD on admission, prisoners, already enrolled in the RESCUE trial, or had non-thermal injuries.

\section{Data Collected}

After informed consent was obtained, data were collected prospectively. For patients already started on RRT prior to approval of this concurrent enrolling study, data were collected retrospectively. Patient demographics, injury characteristics, laboratory data at time of RRT initiation, RRT treatment data, and outcome data were collected. Data were entered into a web-based electronic data management portal (Velos, Inc., Fremont, CA, USA). Data related to RRT treatment included mode of therapy, ordered and delivered therapy dose, AKI stage at initiation (KDIGO criteria), prescribing provider specialty, and method of regional anticoagulation. Outcome data included in-hospital mortality and need for
RRT at discharge. A 6-month follow-up audit was performed to determine which survivors remained on RRT.

\section{Statistical Analysis}

Analysis was performed on de-identified data. $\chi^{2}$ test was utilized for categorical comparisons. Continuous variables were compared using one-way ANOVA. Demographics were expressed as means with standard deviations or medians with minimum and maximum ranges, depending on normality determined via Shapiro-Wilk test. Sample size determinations were calculated utilizing $\chi^{2}$ test with a Yates Correction Factor to attain at least an $80 \%$ power with an alpha of 0.05 . Kaplan-Meier plots were utilized to assess survival impact over time. SPSS 22.0 was utilized for statistical analysis.

\section{Results}

During the study, data from 171 enrolled patients were collected for analysis. One patient was excluded from the analysis for incomplete data. Patients in the cohort had a mean age of $51 \pm 17.4$ years, and $80 \%$ were male. The mean total body surface area burned was $38 \%$ with $24 \%$ being full thickness. Thirty-four percent sustained inhalation injuries. The mean Acute Physiology and Chronic Health Evaluation II score was 26. Ninety-one patients (54\%) were treated with CVVH, 53 (31\%) with continuous venovenous hemodiafiltration, and 26 (15\%) with some form of dialysis. Twenty-three patients were started on continuous venovenous hemodialysis, 2 on intermittent hemodialysis, and 1 on sustained low-efficiency dialysis. Demographics and treatment characteristics were not significantly different between groupings, based on modality (Table 1). Comparisons between survivors and non-survivors can be seen in Table 2. Non-survivors were significantly older with large burns and more likely to sustain an inhalation injury. Survivors were significantly less likely to require vasopressors. Likely related to longer lengths of stay, survivors were also more likely to acquire a ventilator-associated pneumonia.

When comparing patients treated with CVVH versus all other modalities, there was no statistically significant difference in survival; however, the analysis was underpowered (56 vs. $43 \%$; $p=0.124$; power $=0.319$ ) (Fig. 1 ). To adequately detect the presence of the $13 \%$ difference in mortality with an $80 \%$ power, 546 patients would be required. Survival was improved in the subset of patients receiving vasopressors $(n=77)$ at the time of RRT initiation (54 vs. 37\%; $p=0.032$ ) (Fig. 2). For patients sustaining inhalation injury, there was no difference in survival ( 53 vs. $47 \% ; p=0.638$; power $=0.071$ ). There was no statistical survival difference in patients developing acute 
Table 1. Demographics and treatment characteristics

\begin{tabular}{lcccc}
\hline Variable & $\begin{array}{l}\text { Hemofiltration } \\
(n=91)\end{array}$ & $\begin{array}{l}\text { Hemodiafiltration } \\
(n=53)\end{array}$ & $\begin{array}{l}\text { Dialysis } \\
(n=26)^{\mathrm{a}}\end{array}$ & $p$ value \\
\hline Age, years $^{\mathrm{b}}$ & $48(36,65)$ & $54(43,65.5)$ & $53.5(36,64.5)$ & 0.550 \\
Malec $^{\mathrm{c}}$ & $71(78)$ & $44(83)$ & $21(81)$ & 0.766 \\
TBSA, \% $^{\mathrm{b}}$ & $30(15,54.8)$ & $35(16.8,66)$ & $36(28.5,57.8)$ & 0.295 \\
Inhalation injury $^{\mathrm{c}}$ & $26(29)$ & $19(36)$ & $12(41)$ & 0.382 \\
Revised Baux score $^{\mathrm{d}}$ & $90.9 \pm 28.2$ & $100.1 \pm 28.4$ & $97.1 \pm 33.3$ & 0.169 \\
Days from injury to initiation $^{\mathrm{b}}$ & $7(1,15)$ & $3(1,13)$ & $7.5(1.3,22.8)$ & 0.459 \\
${\text { Prescribed therapy rate, } \mathrm{mg} / \mathrm{kg} / \mathrm{h}^{\mathrm{b}}}^{\mathrm{b}}$ & $37.4(28.3,53.9)$ & $39.8(31.1,49.6)$ & $39.0(30.3,59.6)$ & 0.816 \\
${\text { Delivered therapy rate, } \mathrm{mg} / \mathrm{kg} / \mathrm{h}^{\mathrm{b}}}_{\text {KDIGO } 1 \text { at initiation }^{\mathrm{c}}}$ & $34.1(26.1,51.9)$ & $36.9(20.2,51.9)$ & $36.5(18.6,58.1)$ & 0.935 \\
Vasopressors at initiation $^{\mathrm{c}}$ & $22(26.8)$ & $9(17)$ & $6(24)$ & 0.413 \\
\hline
\end{tabular}

CVVHD, continuous venovenous hemodiafiltration; IHD, intermittent hemodialysis; KDIGO 1, Kidney Disease: Improving Global Outcomes Stage 1; SLED, sustained low-efficiency dialysis; TBSA, total body surface area burned. ${ }^{\text {a CVVHD }}(n=23)$, IHD $(n=2)$, SLED $(n=1) .{ }^{\mathrm{b}}$ Median (interquartile range). ${ }^{\mathrm{c}} n(\%) .{ }^{\mathrm{d}}$ Mean $\pm \mathrm{SD}$.

Table 2. Outcome according to patient characteristics and complications

\begin{tabular}{|c|c|c|c|}
\hline Variable & $\begin{array}{l}\text { Survivors } \\
(n=85)\end{array}$ & $\begin{array}{l}\text { Non-survivors } \\
(n=85)\end{array}$ & $p$ value \\
\hline Age, years ${ }^{\mathrm{a}}$ & $47(38,60)$ & $56(36,68)$ & 0.028 \\
\hline Male ${ }^{b}$ & $65(76.5)$ & $71(83.5)$ & 0.338 \\
\hline TBSA, $\%^{\mathrm{a}}$ & $26(14.8,44.5)$ & $44(24.5,68.5)$ & $<0.001$ \\
\hline Inhalation injury ${ }^{\mathrm{b}}$ & $19(22.4)$ & $38(44.7)$ & 0.003 \\
\hline Revised Baux score ${ }^{c}$ & $82.8 \pm 25.8$ & $106.6 \pm 27.8$ & $<0.001$ \\
\hline \multicolumn{4}{|l|}{ KDIGO 1 at initiation ${ }^{b}$} \\
\hline No AKI & $4(4.7)$ & $6(7.1)$ & 0.309 \\
\hline Stage 1 & $14(16.5)$ & $23(27.1)$ & \\
\hline Stage 2 & $16(18.8)$ & $14(16.5)$ & \\
\hline Stage 3 & $51(60)$ & $42(49.4)$ & \\
\hline Vasopressors at initiation ${ }^{b}$ & $31(36.5)$ & $46(54.8)^{\mathrm{d}}$ & 0.036 \\
\hline Central line-associated infection ${ }^{b}$ & $14(16.5)$ & $16(18.8)$ & 0.841 \\
\hline Venous thromboembolism ${ }^{\mathrm{b}}$ & $15(17.7)$ & $12(14.1)$ & 0.675 \\
\hline Ventilator-associated pneumonia ${ }^{b}$ & $37(43.5)$ & $22(25.9)$ & 0.024 \\
\hline
\end{tabular}

KDIGO 1, Kidney Disease: Improving Global Outcomes Stage 1; TBSA, total body surface area burned. AKI, acute kidney injury; TBSA, total body surface area burned. ${ }^{a}$ Median (interquartile range). ${ }^{\mathrm{b}} n(\%) .{ }^{\mathrm{c}} \mathrm{Mean} \pm \mathrm{SD}$. d $n=84$.

lung injury or acute respiratory distress syndrome (ARDS) (Fig. 3).

There was no difference in survival when comparing patients treated with some form of convection to diffusion alone ( 53 vs. $31 \% ; p=0.055$; power $=0.47$ ). Three hundred fifty-one patients would be needed to be meet $80 \%$ power. Parallel to sample attrition, power significantly decreased when analyzing patients requiring vasopressors $(n=77)$. Survival difference did not meet statis- tical significance ( 47 vs. $18 \% ; p=0.061$; power $=0.571$ ) but would require 167 patients to be adequately powered. There was a difference in survival for patients sustaining inhalation injury, as there were unfortunately no survivors in the diffusion group (42 vs. $0 \% ; p=0.005$ ) (Fig. 4).

Therapy dose was analyzed based on delivered dose, comparing $\geq 35 \mathrm{~mL} / \mathrm{kg} / \mathrm{h}$ (HVHF) to standard doses. There was no statistical difference in overall mortality (55 vs. $35 \%$; $p=0.131$; power 0.308 ) (Fig. 5). To give proper 


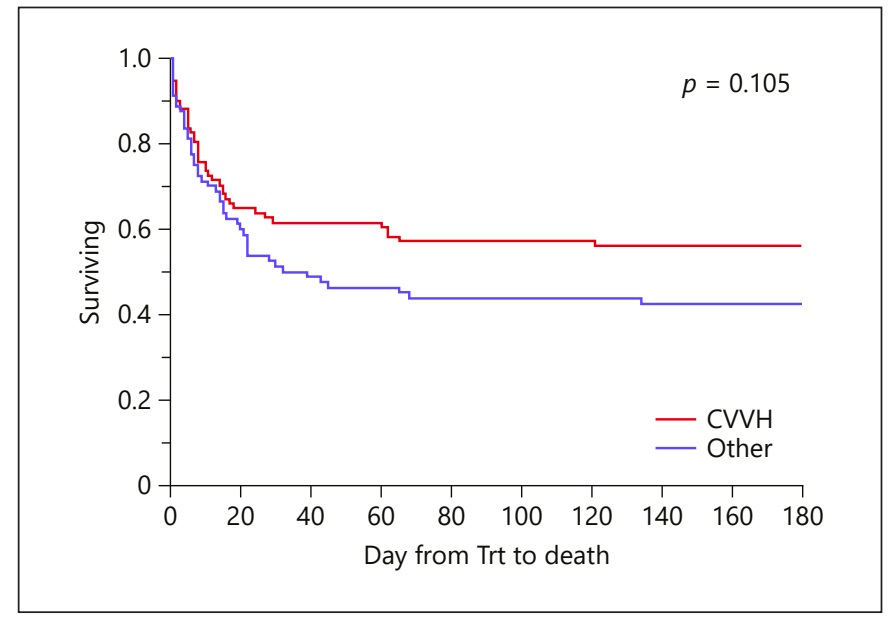

Fig. 1. Kaplan-Meier analysis of entire cohort $(n=170)$ comparing survival of patients receiving CVVH to all other modalities. CVVH, continuous venovenous hemofiltration; Trt, treatment.

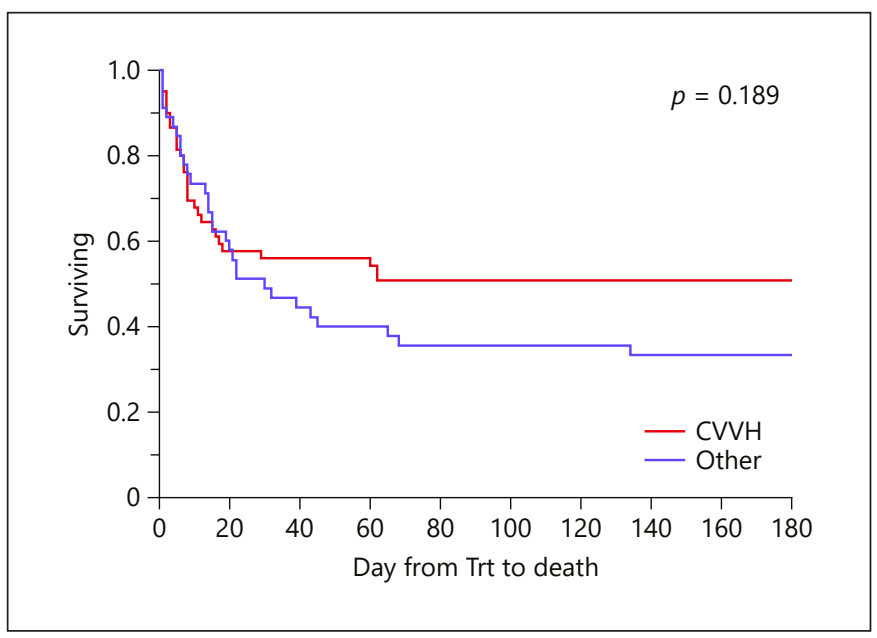

Fig. 3. Kaplan-Meier analysis of patients with acute lung injury/ ARDS $(n=104)$ comparing survival of patients receiving CVVH to all other modalities. CVVH, continuous venovenous hemofiltration; Trt, treatment.

chance to detect the observed $20 \%$ difference in mortality, 257 patients would be needed. For patients receiving vasopressors, HVHF did not provide a statistically significant survival difference ( 54 vs. $37 \%$; $p=0.241$; power $=$ 0.201 ). Assuming only a $15 \%$ survival benefit, 485 patients would need to be enrolled to be adequately powered. Unfortunately, only 23 patients with inhalation in-

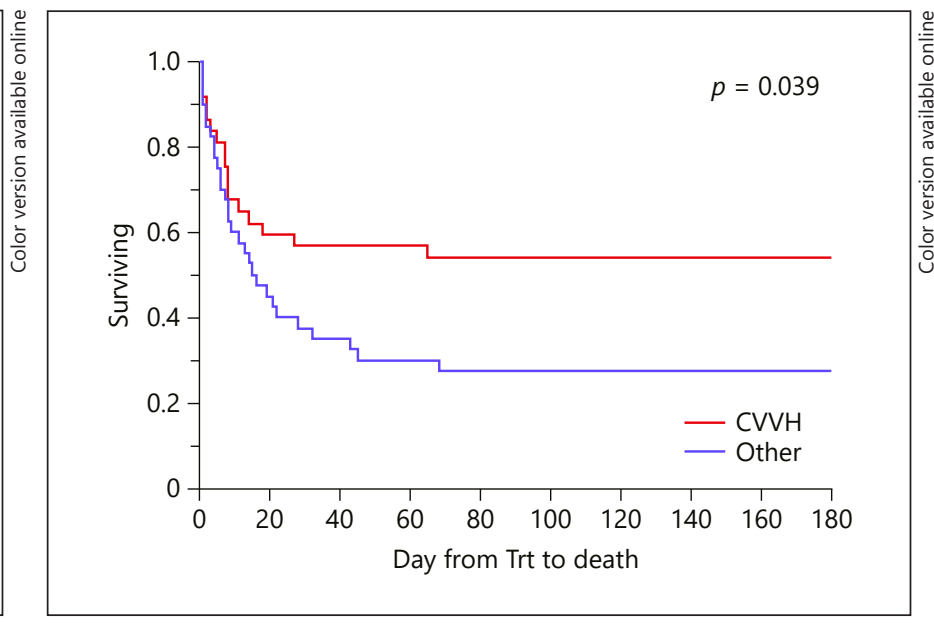

Fig. 2. Kaplan-Meier analysis of patients receiving vasopressors at initiation of RRT ( $n=77$ ) comparing survival of patients receiving $\mathrm{CVVH}$ to all other modalities. CVVH, continuous venovenous hemofiltration; Trt, treatment.

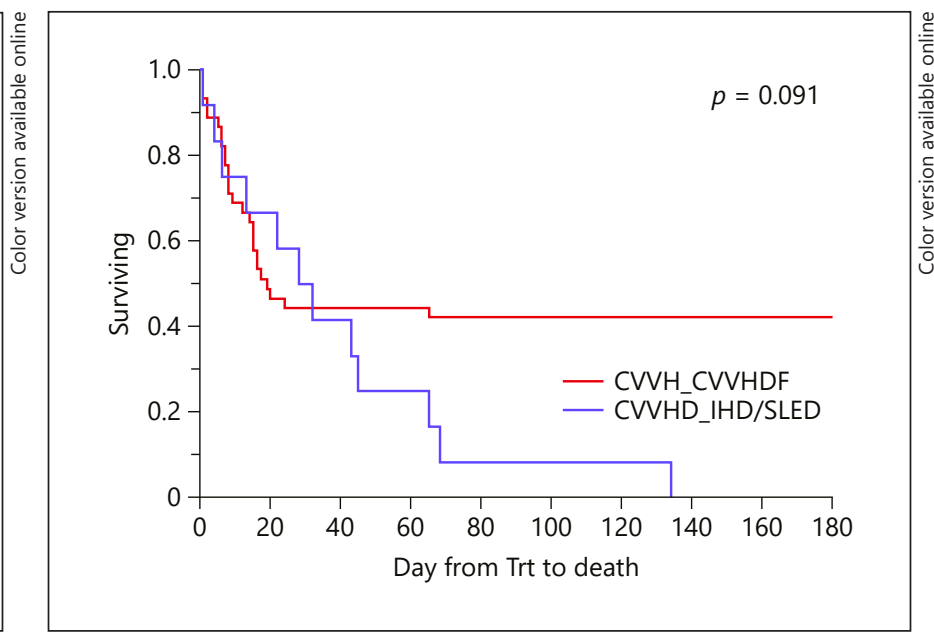

Fig. 4. Kaplan-Meier analysis of patients with inhalation injury $(n=57)$ comparing survival of patients receiving some form of continuous hemofiltration to all other modalities. CVVH, continuous venovenous hemofiltration; CVVHDF, continuous venovenous hemodiafiltration; Trt, treatment; IHD, intermittent hemodialysis; SLED, sustained low-efficiency dialysis.

jury had complete data regarding delivered dose, making it difficult to compare survival. Survival failed to meet statistical significance for patients with inhalation injury receiving some form of $\mathrm{HV}$ convection $(n=4)$ versus all other modalities and lower doses $(n=19)$ (75 vs. $21 \%$; $p=0.067$; power $=0.561$. 




Fig. 5. Kaplan-Meier analysis of patients based on delivered therapy dose $(n=57)$ comparing survival of patients receiving greater than or less than $35 \mathrm{~mL} / \mathrm{kg} / \mathrm{h}$. Trt, treatment

\section{Discussion}

This is the first multicenter cohort study to analyze outcomes based on RRT modality in subsets of burn patients. CVVH demonstrated improved survival in patients requiring vasopressors. Although this observational study does not elucidate the mechanism, the use of convection appears to have benefit in subsets of the burned population, especially in patients requiring vasoactive medications.

Conflicting data exist as to the impact of modality choice on outcomes in critically injured patients with AKI $[10,18,21-26]$. However, a high heterogeneity exists between studies, making generalization and conclusions difficult. This study is the first to analyze mortality in burn patients requiring RRT. While this study was underpowered for some of the subgroup comparisons, the divergence of outcomes is noteworthy. The data within should be helpful for future investigators.

Utilizing convection benefited patients with burn injuries in this study. While cytokine removal has been the theorized mechanism leading to enhanced hemodynamic stability, clinical data supporting this hypothesis remains conflicting [5, 27-31]. In the RESCUE study, patients treated with HVHF had a faster resolution of their shock, but it did not appear related to removal of interleukin (IL) 6 , IL8, IL10, and IL12, interferon- $\gamma$, or tumor necrosis factor- $\alpha$. Of the cytokines chosen to study, none varied over the 48-h measurement period. It is possible different cytokines could be influential or alternative mechanisms could be responsible for the improvement (e.g., metabolic control). Recently, You et al. [32] showed significant removal of cytokines through early application of HVHF in burn patients with sepsis, especially in a subset of patients with very severe burn injuries ( $>80 \%$ total body surface area). The authors also found improved ratios of arterial oxygen partial pressure to fraction of inspired oxygen, improved immunologic function, decreased incidence of sepsis, and improved survival. HVHF was initiated within 3 days postburn and circuits changed routinely at $24 \mathrm{~h}$ regardless of clotting. It is unclear if differences existed in daily fluid balances and, if so, could have impacted the findings. It is likely the ideal marker of most benefit has yet to be identified.

Overall mortality was $50 \%$ in the observational study and $62 \%$ in the interventional study. While still poor, the improvement is noteworthy and consistent with the outcomes trended through the years [12]. In their meta-analysis, Brusselaers et al. [12] noted a median mortality of $80 \%$ for patients with AKI requiring RRT. However, there was a significant improvement in outcomes trended from 1950 to 2010.

Although underpowered, HVHF demonstrated a 20\% decrease in overall mortality in this study, which conflicts with recent literature on the use of higher doses in critically ill patients. A recent systematic review (4 studies) concluded with a low-level recommendation against the use of HVHF over standard doses but stated the inconsistencies in data and significant heterogeneity across studies resulted in low quality of evidence with more studies needed [33]. Conversely, a large meta-analysis of 21 studies reported a significant survival benefit with use of HVHF, especially in the subsets of patients with sepsis and ARDS [34]. The authors assessed for 2 levels of bias and judged none of the included studies to be at low risk of bias.

Perhaps, the "tip of the iceberg theory" should be revisited [28, 35]. Measuring mediator concentrations in the plasma may not necessarily adequately represent concentrations throughout other multiple compartments. Additionally, simply measuring concentrations of cytokines may not be enough, as substantial interpatient variability exists regarding receptor expression and mediator affinity. It may be enlightening to measure and compare mediator differences between multiple compartments within the burn patient. New theories are shifting focus toward beneficial effects attributed to damage-associated molecular pattern (DAMP) removal, but may require the use of an alternative membrane [28, 36, 37]. DAMPs are released after burn injury and have been linked with in- 
flammation and monocyte activation [38]. Simmons et al. [39] demonstrated the presence of DAMPs in reportedly apheresed, leukocyte-reduced transfusion products, and their link to clinical outcomes [40]. Blood product administration is frequently a component of shock resuscitation in burn patients, but was not collected in this cohort [41].

This study was limited by its observational design. Also, data collection occurred both prospectively and retrospectively, based on approval timing of the observational, parallel randomized controlled trial. The likely presence of bias toward prescribing $\mathrm{CVVH}$ in the experienced participating burn centers should be noted. Center effect cannot be excluded, as centers can be biased toward treatment preference. AKI stage was collected, but specific indication was not and is a limitation. Delay in initiation was also much higher than some studies in burn patients showing benefit $[8,32]$. The analysis is limited to the data chosen to be collected, and potential exists for other data to be of value. While history of ESRD requiring dialysis was excluded, presence of other stages of chronic kidney disease was not collected. Specifics regarding management of each case of shock were not collected and could have influenced the results. Similarly, this study was not designed to answer if removal of endotoxin could play a role in survival. While mean prescribed therapy dose was $42 \mathrm{~mL} / \mathrm{kg} / \mathrm{h}$ and evenly divided between $\mathrm{HV}$ and standard doses, delivered dose was not recorded for 73 patients. Due to incomplete data for some subsets, much of the analyses suffer from being underpowered. Baseline characteristics were not different between modality subsets (e.g., revised Baux score); however, there is a chance a difference still exists and a type II error present. The authors hope the power and sample size analysis will aid future researchers in developing studies to answer much needed questions in this population. However, for this multicenter study, the investigators predicted enrollment of 540 patients over the 4 -year study period, demonstrating the difficulty and likely unfeasibility of much larger trials in this population.

\section{Conclusions}

This observational study is the largest cohort to date to perform a subset survival analysis of burn patients started on RRT. This study adds supportive survival data for use of convection-based clearance in septic burn patients, although definitive conclusions cannot be drawn from this study alone. The exact mechanism responsible for the possible benefit remains to be elucidated. Convection may benefit patients with extreme inflammatory pathogenesis, such as burn patients with inhalation injury and acute lung injury/ARDS. More research is needed in high-risk acutely ill populations to delineate why CVVH provides a survival benefit for burn patients with AKI and shock.

\section{Declarations}

The opinions or assertions contained herein are the private views of the authors and are not to be construed as official or as reflecting the views of the Department of the Army or the Department of Defense.

\section{Acknowledgements}

The authors would like to specifically acknowledge tremendous work done by all the RESCUE investigators and support staff: Elsa Coates, Erica A. Pamplin, Cathy A. Rauschendorfer, Sonya Charo-Griego, Victoria D. Hatem, Javance R. Tercero, and Linda S. Welker, United States Army Institute of Surgical Research; Thanh Tran and Kristina R. Bolling, MPH, University of South Florida Tampa General Hospital; Marcia Halerz, Loyola University Medical Center; Amber McIntire and Kiera Nelson, Doctors Hospital Joseph M. Still Burn Center; Karen J. Richey and Claudia Islas, Arizona Burn Center Maricopa Integrated Health Systems; Christina Howard, Peter Gales, and Agnes Burris, University of Texas Southwestern Medical Center. The following is a list of all the ABA RESCUE Investigators listed by clinical site: Booker T. King, MD, Julie A. Rizzo, MD, Jeremy C. Pamplin, MD, Ian R. Driscoll, MD, Evan M. Renz, MD, Jonathan B. Lundy, MD, Elizabeth Mann-Salinas, $\mathrm{PhD}$, and Leopoldo C. Cancio, MD, United States Army Institute of Surgical Research; Carl W. Cruse, MD, Christopher A. McFarren, MD, Kimberly S. Brown, ARNP, David J. Smith Jr., MD, and Rachel A. Karlnoski, PhD, University of South Florida Tampa General Hospital; Arif Showkat, MD, Lekha George, MD, Aneel Kumar, MD, Barbara Birmingham, CRNP, Angela L. Arnold-Ross, RN, and Mary E. Bruce, PA, University of Tennessee Firefighters' Regional Burn Center; Michael J. Mosier, MD, Arthur P. Sanford, MD, David J. Leehey, MD, and Peggie F. Conrad, Loyola University Medical Center; Bruce Friedman, MD, Amy M. Sprague, MD, Robert F. Mullins, MD, Zaheed Hassan, MD, and Joseph R. Shaver, MD, Doctors Hospital Joseph M. Still Burn Center; Kevin N. Fosters, MD, Michael D. Peck, MD, Daniel M. Caruso, MD, and Marlene Albrecht, RN, Arizona Burn Center Maricopa Integrated Health Systems; Steven E. Wolf, MD, Brett D. Arnoldo, MD, Herb A. Phelan, MD, and Ramesh Saxena, MD, University of Texas Southwestern Medical Center; Laura S. Johnson, MD, and Melissa M. McLawhorn, RN, Medstar Washington Hospital Center. Additionally, we are appreciative of the continuous support from the ABA central office: Kimberly A. Hoarle, Janet Turner, Kitty Vineyard, Susan Browning, and Lori Palfalvi; ABA Multi-Center Trials Group: Jeffrey Saffle, MD, Salt Lake, UT, 
and James H. Holmes, MD, Winston-Salem, NC: the Data Coordinating Center, University of California Davis Medical Center, Sacramento, CA: MaryBeth Lawless (Director), Silvia Hughes, and Katrina Falwell.

\section{Statement of Ethics}

IRB approval was granted, and informed consent was given by each patient.

\section{Conflict of Interest Statement}

The authors declare to have no conflicts of interests.

\section{Funding Sources}

This work was funded by the United States Army Medical Research and Material Command (Grant No. W81XWH-09-2-0194).

\section{Author Contributions}

All authors made substantial contributions to the conception, design, and acquisition of data. D.M.H., J.K.A., and K.K.C. made substantial contributions to analysis and interpretation of data. D.M.H. drafted the manuscript. All authors were involved in revising the manuscript. All authors gave approval of the final manuscript to be published.

\section{References}

1 Wald R, McArthur E, Adhikari NK, Bagshaw SM, Burns KE, Garg AX, et al. Changing incidence and outcomes following dialysis-requiring acute kidney injury among critically ill adults: a population-based cohort study. Am J Kidney Dis. 2015;65(6):870-7.

2 Chung KK, Lundy JB, Matson JR, Renz EM, White CE, King BT, et al. Continuous venovenous hemofiltration in severely burned patients with acute kidney injury: a cohort study. Crit Care. 2009;13(3):R62.

3 Chung KK, Coates EC, Hickerson WL, Arnold-Ross AL, Caruso DM, Albrecht M, et al. Randomized controlled evaluation of highvolume hemofiltration in adult burn patients with septic s, acute kidney injury I. Renal replacement therapy in severe burns: a multicenter observational study. J Burn Care Res. 2018;39:1017-21.

4 Tandukar S, Palevsky PM. Continuous renal replacement therapy: who, when, why, and how. Chest. 2019;155(3):626-38.

5 Chung KK, Coates EC, Smith DJ Jr, Karlnoski RA, Hickerson WL, Arnold-Ross AL, et al. Randomized controlled evaluation of high-volume hemofiltration in adult burn patients with septic s, acute kidney injury I. High-volume hemofiltration in adult burn patients with septic shock and acute kidney injury: a multicenter randomized controlled trial. Crit Care. 2017;21:289.

6 Joannes-Boyau O, Honoré PM, Perez P, Bagshaw SM, Grand H, Canivet JL, et al. Highvolume versus standard-volume haemofiltration for septic shock patients with acute kidney injury (IVOIRE study): a multicentre randomized controlled trial. Intensive Care Med. 2013;39(9):1535-46.

7 Park JT, Lee H, Kee YK, Park S, Oh HJ, Han $\mathrm{SH}$, et al. High-dose versus conventional-dose continuous venovenous hemodiafiltration and patient and kidney survival and cytokine removal in sepsis-associated acute kidney injury: a randomized controlled trial. Am J Kidney Dis. 2016;68(4):599-608.
8 Zarbock A, Kellum JA, Schmidt C, Van Aken $\mathrm{H}$, Wempe C, Pavenstädt $\mathrm{H}$, et al. Effect of early vs. delayed initiation of renal replacement therapy on mortality in critically Ill patients with acute kidney injury: the ELAIN randomized clinical trial. JAMA. 2016; 315(20):2190-9.

9 Gaudry S, Hajage D, Schortgen F, MartinLefevre L, Verney C, Pons B, et al. Timing of renal support and outcome of septic shock and acute respiratory distress syndrome. a post hoc analysis of the AKIKI randomized clinical trial. Am J Respir Crit Care Med. 2018;198(1):58-66.

10 Premuzic V, Basic-Jukic N, Jelakovic B, Kes P. Differences in CVVH vs. CVVHDF in the management of sepsis-induced acute kidney injury in critically ill patients. J Artif Organs. 2017;20(4):326-34.

11 Dreyfuss D, Hajage D, Gaudry S. Why ELAIN and AKIKI should not be compared: resolving discordant studies. Am J Kidney Dis. 2017;69(6):864.

12 Brusselaers N, Monstrey S, Colpaert K, Decruyenaere J, Blot SI, Hoste EA. Outcome of acute kidney injury in severe burns: a systematic review and meta-analysis. Intensive Care Med. 2010;36(6):915-25.

13 Hill DM, Smith RR, Hickerson WL, Velamuri SR. 48 analysis of factors impacting mortality in thermal or inhalation injury. J Burn Care Res. 2019 Apr;40(Suppl 1):S34-5.

14 Smith RR, Hill DM, Hickerson WL, Velamuri SR. Analysis of factors impacting length of stay in thermal and inhalation injury. Burns. 2019;45(7):1593-9.

15 Gallagher M, Cass A, Bellomo R, Finfer S, Gattas D, Lee J, et al. Long-term survival and dialysis dependency following acute kidney injury in intensive care: extended follow-up of a randomized controlled trial. PLoS Med. 2014;11(2):e1001601.
16 Palevsky PM, O'Connor TZ, Chertow GM, Crowley ST, Zhang JH, Kellum JA, et al. Intensity of renal replacement therapy in acute kidney injury: perspective from within the acute renal failure trial network study. Crit Care. 2009;13(4):310.

17 Ronco C, Bellomo R, Homel P, Brendolan A, Dan M, Piccinni P, et al. Effects of different doses in continuous veno-venous haemofiltration on outcomes of acute renal failure: a prospective randomised trial. Lancet. 2000; 356(9223):26-30.

18 Vinsonneau C, Camus C, Combes A, Costa de Beauregard MA, Klouche K, Boulain T, et al. Continuous venovenous haemodiafiltration versus intermittent haemodialysis for acute renal failure in patients with multiple-organ dysfunction syndrome: a multicentre randomised trial. Lancet. 2006;368(9533):37985.

19 Saudan P, Niederberger M, De Seigneux S, Romand J, Pugin J, Perneger T, et al. Adding a dialysis dose to continuous hemofiltration increases survival in patients with acute renal failure. Kidney Int. 2006;70(7):1312-7.

20 Tolwani AJ, Campbell RC, Stofan BS, Lai KR, Oster RA, Wille KM. Standard versus highdose CVVHDF for ICU-related acute renal failure. J Am Soc Nephrol. 2008;19(6):1233-8.

21 Uchino S, Bellomo R, Kellum JA, Morimatsu $\mathrm{H}$, Morgera S, Schetz MR, et al. Beginning, ending supportive therapy for the kidney investigators writing C. Patient and kidney survival by dialysis modality in critically ill patients with acute kidney injury. Int J Artif Organs. 2007;30:281-92.

22 Wald R, Friedrich JO, Bagshaw SM, Burns KE, Garg AX, Hladunewich MA, et al. Optimal mode of clearance in critically ill patients with acute kidney injury (OMAKI): a pilot randomized controlled trial of hemofiltration versus hemodialysis: a canadian critical care trials group project. Crit Care. 2012;16(5): R205. 
23 Santoro A, Mancini E, Bolzani R, Boggi R, Cagnoli L, Francioso A, et al. The effect of online high-flux hemofiltration versus low-flux hemodialysis on mortality in chronic kidney failure: a small randomized controlled trial. Am J Kidney Dis. 2008;52(3):507-18.

24 Locatelli F, Karaboyas A, Pisoni RL, Robinson BM, Fort J, Vanholder R, et al. Mortality risk in patients on hemodiafiltration versus hemodialysis: a "real-world" comparison from the DOPPS. Nephrol Dial Transplant. 2018; 33:683-9.

25 Friedrich JO, Wald R, Bagshaw SM, Burns KE, Adhikari NK. Hemofiltration compared to hemodialysis for acute kidney injury: systematic review and meta-analysis. Crit Care. 2012;16(4):R146.

26 AlEnezi F, Alhazzani W, Ma J, Alanazi S, Salib M, Attia M, et al. Continuous venovenous hemofiltration versus continuous venovenous hemodiafiltration in critically ill patients: a retrospective cohort study from a canadian tertiary centre. Can Respir J. 2014; 21(3):176-80

27 Chu LP, Zhou JJ, Yu YF, Huang Y, Dong WX Clinical effects of pulse high-volume hemofiltration on severe acute pancreatitis complicated with multiple organ dysfunction syndrome. Ther Apher Dial. 2013;17(1):78-83.

28 Honore PM, Hoste E, Molnár Z, Jacobs R, Joannes-Boyau O, Malbrain MLNG, et al. Cytokine removal in human septic shock: where are we and where are we going? Ann Intensive Care. 2019;9(1):56.
29 Li L, Bo W, Chen H, XiaoWei L, Hongbao L, Peng Z. Hemoperfusion plus continuous veno-venous hemofiltration in the treatment of patients with multiple organ failure after wasp stings. Int J Artif Organs. 2020;43(3):143-9.

30 Ohchi Y, Goto K, Yasuda N, Koga H, Kitano T. High efficiency removal of cytokines and HMGB-1 by continuous hemofiltration with a dual layered polyethersulfone membrane: an ex vivo study. Ther Apher Dial. 2019;23(2): 173-9.

31 Ronco C, Ricci Z, Bellomo R. Importance of increased ultrafiltration volume and impact on mortality: sepsis and cytokine story and the role for CVVH. EDTNA ERCA J. 2002; (Suppl 2):13-8.

32 You B, Zhang YL, Luo GX, Dang YM, Jiang B, Huang GT, et al. Early application of continuous high-volume haemofiltration can reduce sepsis and improve the prognosis of patients with severe burns. Crit Care. 2018;22(1):173.

33 Borthwick EM, Hill CJ, Rabindranath KS, Maxwell AP, McAuley DF, Blackwood B. High-volume haemofiltration for sepsis in adults. Cochrane Database Syst Rev. 2017;1: CD008075.

34 Junhai Z, Beibei C, Jing Y, Li L. Effect of highvolume hemofiltration in critically Ill patients: a systematic review and meta-analysis. Med Sci Monit. 2019;25:3964-75

35 Cavaillon JM, Munoz C, Fitting C, Misset B, Carlet J. Circulating cytokines: the tip of the iceberg? Circ Shock. 1992;38(2):145-52.
$36 \mathrm{Wu}$ J, Ren J, Liu Q, Hu Q, Wu X, Wang G, et al. Effects of changes in the levels of damageassociated molecular patterns following continuous veno-venous hemofiltration therapy on outcomes in acute kidney injury patients with sepsis. Front Immunol. 2018;9:3052.

37 Honore PM, Jacobs R, Joannes-Boyau O, De Regt J, De Waele E, van Gorp V, et al. Newly designed CRRT membranes for sepsis and SIRS: a pragmatic approach for bedside intensivists summarizing the more recent advances: a systematic structured review. ASAIO J. 2013;59(2):99-106.

38 Rani M, Nicholson SE, Zhang Q, Schwacha MG. Damage-associated molecular patterns (DAMPs) released after burn are associated with inflammation and monocyte activation. Burns. 2017;43(2):297-303.

39 Simmons JD, Lee YL, Mulekar S, Kuck JL, Brevard SB, Gonzalez RP, et al. Elevated levels of plasma mitochondrial DNA DAMPs are linked to clinical outcome in severely injured human subjects. Ann Surg. 2013;258(4):5918 ; .

40 Simmons JD, Lee YL, Pastukh VM, Capley G Muscat CA, Muscat DC, et al. Potential contribution of mitochondrial DNA damage associated molecular patterns in transfusion products to the development of acute respiratory distress syndrome after multiple transfusions. J Trauma Acute Care Surg. 2017;82(6): 1023-9.

41 Cartotto R, Greenhalgh D. Colloids in acute burn resuscitation. Crit Care Clin. 2016; 32(4):507-23. 